\title{
Recent global trends in the prevalence and incidence of dementia, and survival with dementia
}

\author{
Martin Prince ${ }^{1 *}$, Gemma-Claire Ali ${ }^{1,2}$, Maëlenn Guerchet ${ }^{1}$, A. Matthew Prina', Emiliano Albanese ${ }^{3}$ and Yu-Tzu Wu ${ }^{4}$
}

\begin{abstract}
Background: Current projections of the scale of the coming dementia epidemic assume that the age- and sex-specific prevalence of dementia will not vary over time, and that population ageing alone (increasing the number of older people at risk) drives the projected increases. The basis for this assumption is doubtful, and secular trends (that is, gradual decreases or increases in prevalence over long-term periods) are perfectly plausible.

Methods: We carried out a systematic review of studies of trends in prevalence, incidence and mortality for people with dementia, conducted since 1980.

Results: We identified nine studies that had tracked dementia prevalence, eight that had tracked dementia incidence, and four that had tracked mortality among people with dementia. There was some moderately consistent evidence to suggest that the incidence of dementia may be declining in high-income countries. Evidence on trends in the prevalence of dementia were inconsistent across studies and did not suggest any clear overall effect. Declining incidence may be balanced by longer survival with dementia, although mortality trends have been little studied. There is some evidence to suggest increasing prevalence in East Asia, consistent with worsening cardiovascular risk factor profiles, although secular changes in diagnostic criteria may also have contributed.

Conclusions: We found no evidence to suggest that the current assumption of constant age-specific prevalence of dementia over time is ill-founded. However, there remains some uncertainty as to the future scale of the dementia epidemic. Population ageing seems destined to play the greatest role, and prudent policymakers should plan future service provision based upon current prevalence projections. Additional priorities should include investing in brain health promotion and dementia prevention programs, and monitoring the future course of the epidemic to chart the effectiveness of these measures.
\end{abstract}

Keywords: Dementia, Trends, Epidemiology, Projection, Global health, Worldwide, Systematic review, Meta-analysis

\section{Background}

Almost all current projections of the scale of the coming dementia epidemic, including those published by Alzheimer's Disease International (ADI) [1-3], assume that the age- and sex-specific prevalence of dementia will not vary over time, and that population ageing alone (increasing the number of older people at risk)

\footnotetext{
* Correspondence: martin.prince@kcl.ac.uk

${ }^{1}$ The Global Observatory for Ageing and Dementia Care, Health Service \& Population Research Department, Institute of Psychiatry, Psychology and Neuroscience, King's College London, PO 36, David Goldberg Centre, De Crespigny Park, London SE5 8AF, UK

Full list of author information is available at the end of the article
}

drives the projected increases $[1,2,4,5]$. The basis for this assumption is doubtful, and secular trends (that is, gradual decreases or increases in prevalence over longterm periods) are perfectly plausible [6]. The prevalence of any condition (the proportion of the population affected at a point in time) is a product of its incidence and the average duration of the disease episode. The incidence is the rate at which new cases develop within the population. The duration of dementia equates to time from incidence to death, given that recovery is, sadly, not possible. Changes in either or both of these indicators could lead to changes in age-specific prevalence [1]. 
It should be noted that trends in the two indicators may not move in the same direction; for example, reductions in incidence might be accompanied by increases in duration of survival with dementia, or vice versa, the one effect tending to cancel out the other in terms of their overall impact on prevalence. Secular trends may vary among world regions, and among different population subgroups within one country. Experience with changing rates of cardiovascular disease, obesity, diabetes and cancer shows this clearly. Geographic or year of birth variations in adult disease occurrence can be explained by differential exposure during different epochs in life, since as early as conception. Hence, the considerable variability in secular trends for these chronic diseases reflects different degrees of progress in improving public health and access to healthcare, and in strengthening health systems and services to better detect, treat and control these conditions.

A decline in age-specific incidence of dementia, at least in high-income countries, is theoretically possible, driven by changes in exposure to suspected developmental, lifestyle and cardiovascular risk factors for dementia [6]. The 2014 World Alzheimer Report focused upon dementia risk reduction, examining the evidence base for modifiable risk factors for dementia [7]. The strongest evidence for possible causal associations with dementia was for low education in early life, hypertension in midlife, and smoking and diabetes across the life course. In a recent modelling exercise, it was estimated that a $10 \%$ reduction in these and other key risk exposures would lead to an $8.3 \%$ reduction in the prevalence of dementia through 2050, with a $15.3 \%$ reduction in dementia prevalence anticipated in response to a $20 \%$ reduction in exposure prevalence [8]. In most world regions, each generation is better educated than the one before. Although trends differ between countries, sexes, age groups and time periods, there has been a general trend in many high-income countries towards less smoking, falling total cholesterol and blood pressure levels, and increasing physical activity [9]. On the other hand, the prevalence of obesity and diabetes has been increasing in most developed countries. The picture in many low- and middle-income countries is quite different: The trends in cardiovascular health among older people are in an adverse direction [9], with a pattern of increasing stroke [10] and ischaemic heart disease morbidity and mortality [11-13], linked to an epidemic of obesity and increasing blood pressure levels [14]. After a lag period, to the extent that these factors are genuinely causally associated with dementia, one would expect to see corresponding reductions (or increases) in the incidence of dementia.

Secular trends in survival with dementia are difficult to measure. Because dementia has a long and highly variable latency period, estimates from clinical services are confounded by time of diagnosis. If diagnosis is being made at an earlier stage in the disease process, then duration of dementia may appear to be increasing, whereas this may signify only that people with dementia are in contact with services for a higher proportion of the overall disease duration. Trends in cause of death on death certificates provide information on secular changes in the attribution of dementia as a cause of death, but not on the all-cause mortality rate among people with dementia [15]. A proper understanding of trends in survival with dementia will come only from monitoring all-cause mortality rates of those with and without the disease, and the ratio between them (standardised mortality ratio, or hazard ratio) over time. Mortality rates among older people continue to fall in all world regions, and for all age groups, accounting for impressive gains in life expectancy from age 60 years [16]. This is now one of the main drivers of population ageing, particularly but not exclusively in higher-income countries. Whether these overall trends for declining mortality apply equally to people living with dementia is not known. Mortality rates among older people are much higher for those living with dementia. In the 10/66 Dementia Research Group studies in Latin America, India and China, after controlling for age and sex, in a Cox proportional hazards regression, hazard of death was 1.56 to 5.69 times higher in those with dementia (meta-analysed HR 2.80, 95 \% CI 2.48-3.15) [17]. Effect sizes from studies in countries with low or middle incomes (for example, HR 2.83 [95 \% CI 1.10-7.27] in Nigeria [18] and HR 5.16 [95 \% CI 3.747.12] in Brazil [19]) have tended to be slightly higher than those indicated by a meta-analysis of studies principally from countries with high incomes (relative risk 2.63, $95 \%$ CI 2.17-3.21) [20]. If age-standardised mortality rates among people with dementia decline at the same rate as for those without dementia (that is, the adjusted mortality ratio remains constant over time), survival with dementia, and hence disease duration, will increase progressively.

Finally, it should be noted that one of the indications of successful dementia risk reduction may be that the incidence of dementia is deferred to older ages. Thus, the average age of onset may increase over time. Under these circumstances, age-specific or age-standardised mortality for people with dementia may not change, but overall, for all people with dementia, mortality may be higher and survival with dementia shorter, reflecting that onset is occurring closer to the 'natural' end of life. Langa has described this phenomenon as 'the compression of cognitive morbidity' [21], a desirable outcome for public health and individual quality of life, resulting in longer, healthier lives, with fewer years spent in a state of reduced independence and needing care.

At the time of the 2009 World Alzheimer Report, what very few data were available from certain high-income 
countries did not suggest any clear pattern of a decline or increase over time in either the incidence or prevalence of dementia [1, 22, 23]. Our meta-analysis of European studies conducted since 1980 also did not suggest any secular trend in prevalence [4]. Just a few years later, and linked to a greatly increased interest in the potential for prevention of dementia by targeting modifiable risk factors $[24,25]$, the quality and extent of the evidence has expanded greatly, with reports from several studies of trends in dementia prevalence, incidence and/or mortality within defined populations. Such secular comparisons are conceivably more valid because identical or very similar research methodology has been applied within studies over time. Our aim in this paper is to review this evidence, together with regional meta-analyses of trends in dementia prevalence over time. A preliminary version of this review was published in the World Alzheimer Report 2015 [3]. The present version is substantially updated, taking account of studies published since then and other conference abstracts that have now been published as definitive peer-reviewed papers, with different, and, presumably, more appropriate results.

\section{Methods}

Studies of secular trends since 1980 in the prevalence or incidence of dementia or Alzheimer's disease within defined populations were identified from the systematic review of studies of dementia prevalence and incidence conducted by the Global Observatory for Ageing and Dementia Care for the World Alzheimer Reports of 2009 [1] and 2015 [3], and from the World Health Organization 2012 report [26], as well as by hand-searching the references of those relevant studies identified. Any studies that met the sampling and ascertainment eligibility criteria for the reviews of prevalence and incidence were included in this review, with the additional inclusion criterion that methodologies within studies should have been held constant between successive prevalence or incidence waves. We did not stipulate any minimum or maximum interval between waves. We report the crude percentage reduction or increase in prevalence or incidence, and rate of change per year, together with adjusted rate ratios (or hazard or odds ratios) if provided, with adjustment for compositional factors, principally age and sex. For mortality, we conducted an additional search of the PubMed database using the search terms "(dementia or alzheim") AND (mortality or survival) AND trend"*".

\section{Results}

\section{Dementia prevalence}

We identified nine studies that had tracked changes in dementia prevalence over time (Table 1). In one study, the Medical Research Council Cognitive function and Ageing Study (MRC CFAS) [27], there was a statistically significant decline in the prevalence of dementia between 1993 and 2011. This was consistent with a somewhat larger but statistically non-significant decline in the prevalence of dementia in Zaragoza, Spain [28], and with a decline in the prevalence of moderate to severe cognitive impairment seen in the Health and Retirement Study (HRS) in the United States [21]. The annual rates of relative change in prevalence were $-1.7 \%,-3.6 \%$ and $-3.2 \%$ per year, respectively. Set against this, three other studies from Sweden [29, 30] and the United States [31] indicated a stable prevalence of dementia, consistent with shortterm trends in German insurance claims data [32]. In a third Swedish study of short-term trends in dementia prevalence among the oldest old, prevalence had increased by $40 \%$ between 2001 and 2006 [33]. In the Japanese Hisayama study, there was a non-significant $38 \%$ relative increase in the prevalence of dementia between 1985 and 2005 , with a marked increase in the proportion of cases accounted for by Alzheimer's disease [34]. This is consistent with findings from one other Japanese study of secular trends, with a $23 \%$ increase in the prevalence of dementia between 1980 and 2000 [35]. This study was excluded from this review because its ascertainment procedures did not meet the minimum quality criteria we set for our global estimates of dementia prevalence [1]. However, although inadequate, they were held constant between the three waves of the study.

\section{Dementia incidence}

Nine studies had tracked dementia incidence over time (Table 2). Statistically significant reductions in the incidence of dementia were reported in two U.S. populationbased studies: one of African Americans in Indianapolis, IN [36] and the other derived from the Framingham study [37]. Dementia incidence over time was also tracked in one study done in Bordeaux, France [38]. The annual rates of relative change $(-5.5 \%,-1.6 \%$ and $-3.5 \%$, respectively) are broadly consistent with a non-significant $-2.5 \%$ annual rate of relative change in incidence reported in the Rotterdam study [39]. A similar annual rate of decline in dementia incidence $(-3.0 \%)$ was reported in an analysis of German insurance claims data [40], but with only a 3-year interval between the midpoints of the two follow-up periods and with a possibility that trends in help-seeking or clinical diagnosis might have explained the findings. A similar study using comprehensive health information system data for the Canadian province of Ontario suggested a $-0.6 \%$ decline in standardised incidence over a 12-year period (2002-2013) [41]. To the extent that changes in incidence can be inferred from changes in prevalence and mortality, data from repeated surveys in Stockholm, Sweden, are also consistent with a decline in dementia incidence [29]. On the other hand, population-based studies conducted in Chicago, IL, USA 
Table 1 Studies estimating changes in prevalence of dementia or Alzheimer's disease over time

\begin{tabular}{|c|c|c|c|c|c|c|}
\hline Study, setting, age range & Outcomes & Relative change (\%) & Period & $\begin{array}{l}\text { Interval } \\
\text { (years) }\end{array}$ & $\begin{array}{l}\text { Relative change } \\
(\%) \text { per year }\end{array}$ & Other findings/notes \\
\hline $\begin{array}{l}\text { 1. United Kingdom, MRC CFAS, } \\
65 \text { years and older [27] }\end{array}$ & $\begin{array}{l}\text { Dementia (GMS- } \\
\text { AGECAT) }\end{array}$ & $30 \%$ reduction AOR $0.7(0.6-0.9)$ & $1993-2011$ & 18 years & $-1.7 \%$ & $\begin{array}{l}\text { Bigger dementia prevalence reduction in older } \\
\text { age groups. Reduction in the proportion of } \\
\text { older people, and people with dementia living } \\
\text { in care homes. Increased prevalence of } \\
\text { dementia among care home residents. }\end{array}$ \\
\hline
\end{tabular}

\begin{tabular}{|c|c|c|c|c|}
\hline $\begin{array}{l}\text { 2. Zaragoza, Spain, } 65 \text { years } \\
\text { and older [28] }\end{array}$ & Dementia (DSM-IV) & $\begin{array}{l}\text { Non-significant } 25 \% \text { reduction } \\
\text { AOR } 0.75(0.56-1.02) \\
\text { Women AOR } 1.02(0.69-1.51) \\
\text { Men AOR } 0.40(0.25-0.65)\end{array}$ & 1988-1995 & 7 years \\
\hline $\begin{array}{l}\text { 3RS, nationally representative, } \\
\text { Jnited States, } 70 \text { years and older }\end{array}$ & $\begin{array}{l}\text { Moderate/severe } \\
\text { cognitive impairment }\end{array}$ & 29 \% reduction AOR $0.65(0.58-0.73)$ & 1993-2002 & 9 years \\
\hline
\end{tabular}

dementia among care home residents.

[21]

4. United States, Indianapolis, IN, Dementia (DSM-III-R) Stable $6.8 \%$ vs. $7.5 \%$ (dementia African Americans, 65 years and AD

older [31]

5. Stockholm, Sweden, 75 years and older [29]

6. Germany, insurance claims data, 65 and older [32]
Dementia (DSM-III-R)

Dementia (ICD-10) (0.68-1.05)

Stable prevalence in all age groups and both sexes, other than women aged 75-84 years AOR $0.97(0.95-0.98)$ criteria
1991-2002 11 years No trend

$p=0.35) 5.5 \%$ vs. $6.8 \%(\mathrm{AD} p=0.26)$

1988-2002

14 years

3 years

2007-2009 aged $75-84$ years)

Bigger (and statistically significant) dementia prevalence reduction in men. No changes observed in education level.

Increases in levels of education, significantly fewer IADL limitations but higher rates of cardiovascular risk factors and cardiovascular disease, including diabetes, hypertension, obesity and heart disease. Education differences accounted for $43 \%$ of the prevalence difference between time points. Residents of care homes were excluded from the 1993 wave. The $6.2 \%$ of 2002 respondents who were residents of care homes were also excluded from the comparative analysis. This may have biased the comparison, if transition to care homes was reserved for those with more severe dementia at the later time point.

Increases in levels of hypertension, diabetes and stroke, but also higher levels of treatment, consistent with national trends for African Americans over this time period. Some differences in recruitment procedures, and a higher refusal rate in 2002.

Much higher levels of education at the second time point.

This study used claims data of the largest public health insurance company in Germany. The data contained complete inpatient and outpatient diagnoses according to ICD-10 For the analysis of prevalence, age-specific prevalence was estimated for the years 2007, 2008 and 2009. Secular trends in clinical diagnosis or help-seeking cannot be excluded.

Higher education level, better results on cognitive tests, better socioeconomic status, better treatment of vascular risk factors and better general physical health in the later-born cohorts

$\begin{array}{llll}\text { Age } 70 \text { years M } 1.7 \% \text { vs. } 0.9 \% \text { F } 2.2 \% & 1976-2000 & 25 \text { years }\end{array}$

vs. $3.7 \%$ Age 75 years M $6.8 \%$ vs. $6.9 \%$ Aged 75 years Aged 75 years

F $3.8 \%$ vs. $5.3 \% \quad 1976-2005 \quad 30$ years 
Table 1 Studies estimating changes in prevalence of dementia or Alzheimer's disease over time (Continued)

\begin{tabular}{|c|c|c|c|c|c|c|}
\hline $\begin{array}{l}\text { 8. Umea, Sweden, } 85 \text { years and } \\
\text { older [33] }\end{array}$ & Dementia (DSM-IV) & $40 \%$ increase $(p=0.001)$ & $2001-2006$ & 5 years & $+8.0 \%$ & $\begin{array}{l}\text { Prevalence differences not adjusted for other } \\
\text { covariates, but age distribution was similar. } \\
\text { Increase in the prescription of antihypertensive } \\
\text { and statin drugs, cholinesterase inhibitors, and } \\
\text { more heart surgery. }\end{array}$ \\
\hline $\begin{array}{l}\text { 9. Japan, Hisayama, aged } \\
65 \text { years and older [34] }\end{array}$ & Dementia, AD & $\begin{array}{l}38 \% \text { increase (dementia) AOR } 1.34 \\
(0.97-1.87) 255 \% \text { increase (AD) } 3.28 \\
(1.75-6.14)\end{array}$ & 1985-2005 & 20 years & $\begin{array}{l}+1.9 \% \text { (dementia) } \\
+12.8 \% \text { (AD) }\end{array}$ & $\begin{array}{l}\text { Ratio of } A D / N a D \text { increasing from } 0.5 \text { in } \\
1985 \text { to } 1.4 \text { in } 2005 .\end{array}$ \\
\hline
\end{tabular}

AD Alzheimer's disease, AGECAT Automated Geriatric Examination for Computer Assisted Taxonomy, AOR adjusted odds ratio, DSM Diagnostic and Statistical Manual of Mental Disorders, GMS Geriatric Mental State Examination, HRS Health and Retirement Study, IADL instrumental activities of daily living, ICD International Classification of Diseases, MRC CFAS Medical Research Council Cognitive function and Ageing Study, VaD vascular dementia 
Table 2 Studies estimating changes in the incidence of dementia or Alzheimer's disease over time

\begin{tabular}{|c|c|c|c|c|c|c|}
\hline Study, setting, age range & Outcomes & Relative change (\%) & Period & $\begin{array}{l}\text { Interval between } \\
\text { incidence cohorts } \\
\text { (years) }\end{array}$ & $\begin{array}{l}\text { Relative change } \\
\text { (\%) per year }\end{array}$ & Other findings \\
\hline \multicolumn{7}{|l|}{ Directly observed } \\
\hline $\begin{array}{l}\text { 1. Indianapolis, IN, USA, } \\
\text { African Americans, } 65 \text { years } \\
\text { and older [36] }\end{array}$ & $\begin{array}{l}\text { Dementia (DSM-III-R) } \\
\text { AD }\end{array}$ & $\begin{array}{l}\text { Dementia } \\
3.6 \% \text { per annum }(3.2-4.1 \%) \text { vs. } \\
1.4 \% \text { per annum }(1.2-1.7 \%) \\
61 \% \text { reduction } \\
\text { AD } \\
2.5 \% \text { per annum }(2.1-2.9 \%) \text { vs. } \\
1.3 \% \text { per annum }(1.0-1.5 \%) \\
48 \% \text { reduction }\end{array}$ & 1991-2002 & 11 years & $\begin{array}{l}\text { Dementia } \\
-5.5 \% \\
\text { AD } \\
-4.4 \%\end{array}$ & $\begin{array}{l}\text { Biggest reduction in youngest age groups. } \\
\text { See also notes for study } 4 \text { in Table } 1 .\end{array}$ \\
\hline $\begin{array}{l}\text { 2. Framingham, MA, USA, } \\
60 \text { years and older [37] }\end{array}$ & $\begin{array}{l}\text { Dementia DSM-IV } \\
\text { AD (NINCDS-ADRDA) } \\
\text { VaD (NINDS-AIREN); } \\
\text { diagnoses by consensus } \\
\text { review panel }\end{array}$ & $\begin{array}{l}\text { Dementia } \\
44 \% \text { reduction } \\
\text { AHR } 0.56(0.41-0.77) \\
\text { AD } \\
30 \% \text { reduction } \\
\text { AHR } 0.70(0.48-1.03) \\
\text { VaD } \\
55 \% \text { reduction } \\
\text { AHR } 0.45(0.23-0.87)\end{array}$ & 1980-2006 & 26 years & $\begin{array}{l}\text { Dementia } \\
-1.7 \% \\
\mathrm{AD} \\
-1.2 \% \\
\mathrm{VaD} \\
-2.1 \%\end{array}$ & $\begin{array}{l}\text { Biggest reduction in youngest age groups. } \\
\text { No reduction among the least educated. } \\
\text { Significant improvements in education status; } \\
\text { use of antihypertensive and statin medication; } \\
\text { blood pressure and HDL levels; and prevalence } \\
\text { of smoking, heart disease and stroke; however, } \\
\text { prevalence of obesity and diabetes increased. }\end{array}$ \\
\hline $\begin{array}{l}\text { 3. Bordeaux, France, } 65 \text { years } \\
\text { and older [38] }\end{array}$ & $\begin{array}{l}\text { Algorithm diagnosis } \\
\text { (using MMSE score } \\
\text { and IADL only) } \\
\text { Clinical diagnosis } \\
\text { 'based upon' } \\
\text { DSM-IIIR/DSM-V }\end{array}$ & $\begin{array}{l}\text { Algorithmic diagnosis } \\
\text { Overall AHR 0.65 (0.53-0.81) } \\
\text { Women AHR 0.62 (0.48-0.80) } \\
\text { Men AHR } 1.10(0.69-1.78) \\
\text { Clinical diagnosis } \\
\text { Overall } 0.92(0.73-1.15) \\
\text { Women } 0.90(0.69-1.17) \\
\text { Men } 1.21(0.76-1.93) .\end{array}$ & $\begin{array}{l}1988 / 1989-1998 / \\
1999 \text { and } 1999 / \\
2001-2009 / 2010\end{array}$ & 10 years & $\begin{array}{l}\text { Overall } \\
-3.5 \% \\
\text { Women } \\
-3.8 \%\end{array}$ & $\begin{array}{l}\text { Compared with the earlier cohort, the later } \\
\text { cohort had more education, a higher BMI, a } \\
\text { lower prevalence of stroke, and were less } \\
\text { likely to be a current and more likely to be } \\
\text { former smokers. More use of antihypertensive } \\
\text { and lipid-lowering drugs. At baseline, they } \\
\text { were less disabled on the } 4 \text {-item IADL score } \\
\text { and had higher MMSE scores. } \\
\text { Differences in education, vascular factors and } \\
\text { depression accounted only to some extent } \\
\text { for this reduction (overall AHR } 0.77,95 \% \mathrm{Cl} \\
0.61-0.97 \text {; women AHR } 0.73,95 \% \mathrm{Cl} 0.57-0.95 \text { ). }\end{array}$ \\
\hline $\begin{array}{l}\text { 4. Rotterdam, the Netherlands, } 60- \\
90 \text { years [39] }\end{array}$ & Dementia (DSM-III-R) & $\begin{array}{l}\text { Non-significant } 25 \% \text { reduction } \\
\text { RR } 0.75 \text { (0.56- } 1.02)\end{array}$ & 1990-2000 & 10 years & $-2.5 \%$ & $\begin{array}{l}\text { Hypertension, diabetes and obesity increased. } \\
\text { Higher education. More diabetes treatment, } \\
\text { more anti-thrombotics and much more } \\
\text { statins. More past but less current smoking. } \\
\text { Substantial reduction in overall mortality: } \\
\text { HR } 0.63 \text { (0.52-0.77). }\end{array}$ \\
\hline
\end{tabular}


Table 2 Studies estimating changes in the incidence of dementia or Alzheimer's disease over time (Continued)

\begin{tabular}{|c|c|c|c|}
\hline $\begin{array}{l}\text { 5. Germany, insurance claims } \\
\text { data, } 65 \text { years and older [40] }\end{array}$ & $\begin{array}{l}\text { Dementia (ICD-10), or } \\
\text { using cholinesterase } \\
\text { inhibitors or memantine }\end{array}$ & $\begin{array}{l}9 \% \text { reduction } \\
\text { Men } 0.91(0.85-0.97) \\
\text { Women } 0.91(0.87-0.95)\end{array}$ & $\begin{array}{l}2004-2007 / \\
2007-2010\end{array}$ \\
\hline
\end{tabular}

inhibitors or memantine Women $0.91(0.87-0.95)$

\begin{abstract}
Dementia diagnosis
(ICD-9 or ICD-10) or

$7.4 \%$ reduction; statistical

significance of trend not

reported
\end{abstract}

2002-2013

12 years

prescription

discharge and ambulatory reported [41]

7. Chicago, IL, USA [31]

8. Ibadan, Nigeria [52]

Inferred

9. Stockholm, Sweden

75 years and older [29]
$A D$

Dementia (DSM-III-R) $A D$

Dementia (DSM-III-R)
Stable

OR $0.97(0.90-1.04)$

Stable

Dementia

$1.7 \%$ per annum (1.4-2.0\%) vs.

$1.4 \%$ per annum (1.1-1.6\%)

$\mathrm{AD}$

$1.5 \%$ per annum (1.2-1.8 \%) vs.

$1.0 \%(0.7-1.2 \%)$
$-3.0 \%$

This study used claims data of the largest public health insurance company in Germany. The data contained complete inpatient and outpatient diagnoses according to ICD-10 codes. For the analysis of incidence, two independent age-stratified samples were taken, the first comprising 139,617 persons in 2004 with follow-up until 2007, the second with 134,653 persons in 2007 with follow-up until 2010. Secular trends in clinical diagnosis or help-seeking cannot be excluded.

This study used claims data of the single state-provided insurance plan and comprehensive hospital admission, comprehensive hospital admission,
ambulatory care and drug prescription ambulatory care and drug prescription
databases. Annual incidence rates, age- and databases. Annual incidence rates, age- and sex-standardised, are reported for each year
between 2002 and 2013. The trend is not linear, and statistical significance is not reported. Secular trends in clinical diagnosis or help-seeking cannot be excluded.

AD Alzheimer's disease, AHR adjusted hazard ratio, BMI body mass index, DSM Diagnostic and Statistical Manual of Mental Disorders, HDL high-density lipoprotein, IADL instrumental activities of daily living,

ICD International Classification of Diseases, MMSE Mini Mental State Examination, NINCDS-ADRDA National Institute of Neurological and Communicative Disorders and Stroke and the Alzheimer's Disease and Related

Disorders Association, NINDS-AIREN National Institute of Neurological Disorders and Stroke and Association Internationale pour la Recherche et l'Enseignement en Neurosciences, RR relative risk, VaD vascular dementia 
[31], and Ibadan, Nigeria [36], indicated a stable incidence of dementia over 11-year periods. One further study, in which researchers reported a stable incidence of dementia in Beijing, China, was excluded from the review because it used slightly different diagnostic criteria at the two time points [42].

\section{Dementia mortality}

In only four of the studies did the researchers take the opportunity to study or report changes in mortality and/ or survival among people with dementia, or the ratio of mortality rates between those with and without dementia (Table 3). In the Rotterdam study [39], overall mortality had declined by $37 \%$ in the 10 years between the two cohorts, but this was not reported with stratification by dementia status. In the HRS in the United States, as well as in the Stockholm study [29], the mortality ratio for dementia remained relatively stable over time, suggesting that, under the assumption that mortality rates were falling among those without dementia, there would have been similar rates of decline for those living with dementia. This was clearly demonstrated in the Stockholm study, where an absolute decline in mortality rates of $30 \%$ over 14 years was seen for those with and without dementia, for both sexes [29]. The relationship between trends in prevalence, incidence and mortality remain unclear, partly because in most of the eligible studies only some of these parameters were directly observed. Only in the German insurance claims data were changes in prevalence, incidence and mortality reported, but these are mutually inconsistent, perhaps because different samples and time periods were used for the prevalence [32] and incidence and/or mortality trend analyses [40]. In marked contrast to other studies, a precipitous increase in mortality rates among people with dementia, particularly women, was noted over a short time interval [40]. In Stockholm (where prevalence and mortality were observed) [29], and in Indianapolis, IN, USA (where prevalence and incidence were observed) [31,36], findings are consistent with declining incidence but stable prevalence, accounted for by increasing duration of dementia (declining dementia mortality).

\section{Secular trends within regions estimated from meta-analyses of individual studies}

Another approach to estimating secular trends involves combining evidence from all studies conducted within a particular country or region, using a meta-analytical approach and meta-regression to estimate the effect of time of study upon prevalence. This approach was used in the 2009 ADI World Alzheimer Report to estimate secular trends in dementia prevalence in Europe [1]. One problem with such exercises is that, in contrast to the studies previously reviewed, which hold such factors constant, there is inevitably considerable heterogeneity in the nature of the population studied and the methods used for the surveys, which may in turn affect the prevalence recorded. It is therefore important, to the extent possible, to control for such effects in the meta-regression. In the European meta-analyses, there was no evidence for a trend in prevalence between 1980 and 2008 [4], and this held true when the evidence base was updated to include studies conducted through 2015 for the 2015 World Alzheimer Report [3].

East Asia is the one other world region with sufficiently numerous prevalence studies to permit meta-regression and estimation of secular trends in dementia prevalence. A study of secular trends in Japan (part of the adjacent Asia Pacific high-income region) reported a tendency towards increasing prevalence, but this was based on only eight data points, including the four waves of the Hisayama study [34], and did not control for study methodology [43]. A systematic review and meta-analysis of 11 population-based prevalence studies conducted in South Korea since 1990 identified a trend towards a decrease in the prevalence of dementia until 2000-2005, with a subsequent increase, but with no statistically significant temporal variation, having adjusted for sample composition and study methodological quality [44]. The East Asia evidence base and the population of older people at risk is dominated by China, the focus of one recent meta-analysis [45], while a second metaanalysis also included studies conducted in Hong Kong and Taiwan [46]. Estimates taken from the China meta-analysis suggested a $46 \%$ relative increase in age-standardised prevalence from 1990 to $2010(+2.3 \%$ per year), while in the wider review the increase was $171 \%$ from studies conducted in the pre-1990 period to 2005-2012 (a prevalence of $2.1 \%$ pre-1990, $3.4 \%$ for $1990-1994,3.9 \%$ for $1995-$ 1999, $4.4 \%$ for $2000-2004$ and $5.7 \%$ for 2005-2012). However, in that study, the secular trend was considerably reduced, to $72 \%$, and was no longer statistically significant, having controlled for study methodology (1.8 \% pre-1990, $2.5 \%$ for 1990-1994, $2.1 \%$ for $1995-$ 1999, $2.4 \%$ for $2000-2004$ and $3.1 \%$ for $2005-2012$ ).

The most important potential confounder appeared to be the choice of dementia diagnostic criteria. Older studies tended to use criteria from the Diagnostic and Statistical Manual of Mental Disorders, Third Edition (DSM-III), the DSM-III-R, or the International Classification of Diseases, Tenth Revision, which then tended to record a lower prevalence of dementia than those more recent studies that used DSM-IV dementia, 10/66 dementia criteria or Geriatric Mental State Examination (GMS)-Automated Geriatric Examination for Computer Assisted Taxonomy (AGECAT) criteria. For the purposes of estimating current dementia prevalence, whether the higher estimates for the most recent period are explained by real underlying secular trends or the use of more up- 
Table 3 Changes in mortality among people with dementia

\begin{tabular}{|c|c|c|c|c|c|}
\hline Study, setting, age range & Outcomes & $\begin{array}{l}\text { Change in mortality and/or mortality hazard } \\
\text { ratio }\end{array}$ & Period & $\begin{array}{l}\text { Interval } \\
\text { (years) }\end{array}$ & Other findings/notes \\
\hline \multicolumn{6}{|l|}{ Directly observed } \\
\hline 1. United States, HRS [21] & Mortality hazard ratio & $\begin{array}{l}\text { Non-significant increase, from HR } 2.53 \text { to } 3.11 \text {, } \\
p=0.09\end{array}$ & 1993-2002 & 9 years & $\begin{array}{l}\text { No report of absolute mortality rates, stratified or unstratified. } \\
\text { However, given a presumed decline in overall mortality, it } \\
\text { seems likely that mortality also declined among people with } \\
\text { dementia, but to a slightly lesser extent }\end{array}$ \\
\hline \multirow[t]{2}{*}{ 2. Stockholm, Sweden [29] } & Mortality hazard ratio & Stable HR: 2.42 (2.03-2.87) vs. 2.47 (2.03-3.00) & \multirow[t]{2}{*}{ 1988-2002 } & \multirow[t]{2}{*}{14 years } & \multirow{2}{*}{$\begin{array}{l}\text { Secular trend similar ( } 30 \% \text { reduction in mortality) to that for } \\
\text { those with no dementia, and for both sexes }\end{array}$} \\
\hline & $\begin{array}{l}\text { Mortality rate among people } \\
\text { with dementia }\end{array}$ & $\begin{array}{l}29 \% \text { reduction in mortality (HR } 0.71,95 \% \mathrm{Cl} \\
0.57-0.88 \text { ) adjusted for age, sex, education } \\
\text { and MMSE score }\end{array}$ & & & \\
\hline $\begin{array}{l}\text { 3. Germany, insurance claims } \\
\text { data, } 65 \text { years and older [32] }\end{array}$ & $\begin{array}{l}\text { Mortality rate among people } \\
\text { with dementia }\end{array}$ & $\begin{array}{l}20 \% \text { increase in mortality among women } \\
\text { with dementia }(p<0.0001) \\
\text { Non-significant } 11 \% \text { increase in mortality } \\
\text { among men with dementia ( } p=0.75)\end{array}$ & 2004-2007 & 3 years & $\begin{array}{l}\text { Mortality among women without dementia remained } \\
\text { constant over the two cohorts, while there was a } \\
\text { non-significant } 4 \% \text { decline in mortality rates among } \\
\text { men without dementia. These findings would suggest } \\
\text { an increase in the mortality hazard ratio associated } \\
\text { with dementia, greater for women than for men. }\end{array}$ \\
\hline \multicolumn{6}{|l|}{ Inferred } \\
\hline $\begin{array}{l}\text { 4. Indianapolis, IN, USA, African } \\
\text { Americans, } 65 \text { years and older } \\
{[31,36]}\end{array}$ & Dementia duration & $\begin{array}{l}\text { Increase in survival with dementia can be } \\
\text { inferred from stable prevalence of dementia } \\
\text { [31], but } 55 \% \text { fall in incidence [36] }\end{array}$ & $1991-2002$ & 11 years & $\begin{array}{l}\text { Extrapolation from reported prevalence and incidence } \\
\text { rates at the two time points suggests that survival time } \\
\text { with dementia is } 2.4 \text { times longer for the second cohort. }\end{array}$ \\
\hline
\end{tabular}


to-date and valid diagnostic criteria, or both, is immaterial. However, for the purposes of forecasting future trends in prevalence and numbers in the region, the distinction is clearly crucially important [47]. As previously indicated, there is evidence that cardiovascular health is deteriorating among older people in China [11], a trend also evident in other middle-income countries [9]. The prevalence of smoking among adult men in China is among the highest in the world, and an epidemic among younger women is well underway [48]. Rapid dietary transition is leading to an epidemic of obesity and cardiometabolic disease [49]. A recent modelling exercise assessed the likely impact of recent increases in obesity among middle-aged Chinese on dementia prevalence, assuming a causal link with dementia. The authors of that study concluded that future dementia prevalence in China may have been underestimated by up to $19 \%$, given the additional impact of epidemiologic transition [50]. The relative contributions of changes in diagnostic criteria, as well as changes in risk factor exposure, both associated with the time that the study was conducted, are uncertain and cannot be resolved with currently available data.

\section{Discussion}

We have updated our recent work on the global burden of dementia and reviewed the entirety of the current global evidence on trends in the prevalence, incidence, and survival with or mortality due to dementia, using data from studies in which investigators had monitored these indicators over time in defined populations with fixed survey and dementia ascertainment methodologies. We also reviewed regional meta-analyses in which researchers had sought to estimate regional trends in prevalence across studies, conducted in various sites and using diverse methods. The present review is the most comprehensive such study to date.

There is no clear evidence from this review to justify a departure from the current position of assuming constant age-specific dementia prevalence when making projections of the numbers likely to be affected in the future [3]. The evidence for a declining trend in the incidence of dementia, at least in high-income countries, is somewhat more consistent, although still patchy, and as yet thinly evidenced. Although the evidence on changes in survival in those with dementia is extremely limited, it is plausible that the effects of a reduced incidence upon prevalence are likely to be offset by a longer survival of those living with dementia.

\section{Potential for prevention}

The future course of the global dementia epidemic through to 2050 is likely to depend, at least to some extent, upon the success or otherwise of continuing efforts to improve public health $[7,25]$. Those who will be old in 2050 were born around the 1970s and have already received their basic education. They are now in their fourth and fifth decades of life, a crucial 'sensitive period' in which evidence suggests that efforts to prevent, detect and control obesity, hypertension, diabetes and dyslipidaemia are likely to have maximum positive impact upon brain health and dementia risk in later life $[7,25]$. Such public health strategies, alongside secular improvements in education, are plausibly likely to result in a progressive decline in age-specific incidence of dementia in high-income countries, the magnitude of which is currently uncertain.

\section{The important impact of survival with dementia}

Whether declining incidence is accompanied by a decline in the age-specific prevalence of dementia will depend upon any coincident changes in survival and/or mortality patterns of people living with dementia, which are difficult to predict on the basis of current data. If the onset of dementia occurs close to the end of the natural lifespan, fewer years may be lived with dementia. Two studies suggest that decline in incidence may be greater in younger age groups, suggesting that the incidence of dementia may be being deferred into older age [51, 52]. This may be consistent with the observation of an increasing prevalence of dementia among the oldest old in one Swedish study [33], but it is inconsistent with the observation from the MRC CFAS study of greater reductions of dementia prevalence among older age groups [27]. Since most of the public health interventions that have been proposed to reduce the incidence of dementia (for example, tobacco control, and prevention and treatment of hypertension) also have benefits in reducing incidence and mortality due to other chronic diseases, one should expect that reductions in prevalence arising from reduced incidence of dementia may be offset, at least to some extent, by reduced mortality and longer survival with dementia [53]. Most of the more plausible scenarios are more consistent with either a stable or a modestly increasing disease prevalence [53, 54]. Of concern, current evidence of adverse trends in cardiovascular risk factors and morbidity in lowand middle-income countries are consistent with a future increase in age-specific incidence and prevalence of dementia in those regions.

Other factors, such as improvements in standards of health and social care for people with dementia as well as provision or withholding of life-prolonging critical interventions, might also be expected to have an influence on mortality rates among people living with dementia. In well-resourced, advanced healthcare settings, there is growing awareness that critical interventions should not be withheld simply because someone has dementia when these would improve quality of life. At the same time, in the context of end-of-life care, the focus should be on 
palliation to improve quality of life, and interventions that merely prolong life with risk of harm to the patient should be withheld [55]. In low- and middle-income countries, there is evidence that people with dementia currently have particular problems in accessing healthcare that might benefit their health and survival [56].

\section{Implications for future research}

Studies that use fixed methodology to estimate changes in dementia prevalence, incidence and mortality over time, in defined populations, are uniquely valuable assets. It is important that more such studies be commissioned. The most valuable will be those that track all three parameters over time, which none of the studies reviewed in this paper did. Surveys with nationally representative samples will have the greatest generalisability and the greatest potential to both inform and track the impact of national policies. Where trends are observed, it will be important to relate these to compositional changes in the population, particularly to changes in levels of exposure to critical risk factors. However, in very few studies have researchers made a comprehensive assessment of such compositional factors and their changes over time, and in only three studies did investigators attempt to attribute changes in dementia frequency to changes in risk factor exposure $[21,37,38]$. It is clearly important that such studies do, as far as possible, hold methodology constant. Several of those reviewed here did make small changes between waves, the effect of which upon the observed trends cannot be determined with complete confidence [27, 31]. Diagnostic criteria change over time, but these too must be held constant to make meaningful comparisons, a problem that can be surmounted by using the updated criteria alongside the original criteria, where feasible and appropriate. A more intractable problem is the probable changes in clinician training, practice and opinions regarding the operationalisation of diagnostic criteria [38, 47]. This may also be countered through the application of structured assessments and diagnostic algorithms, such as the AGECAT computerised algorithm linked to the Geriatric Mental State [57], as employed in the MRC CFAS studies [27], or the 10/66 Dementia Research Group's cross-culturally validated diagnostic algorithm $[58,59]$. Finally, the potential for selection bias due to declining participation rates and increasing attrition rates in cohort studies needs to be carefully considered [27].

In previous modelling exercises, researchers have sought to predict what might happen to the future prevalence of dementia, given our best estimates of risk associations and possible changes in those risk factor profiles over time $[8,50]$. In the light of the present review, these estimations appear overoptimistic. An alternative approach is to observe and correlate actual changes in risk factor profiles and dementia incidence over time.
This is a well-established modelling approach in the cardiovascular disease field and has contributed greatly to understanding of the potential for prevention, and the attribution of changes in disease incidence to specific factors, to further guide prevention strategies [60-62]. Of note, the three studies in this review in which investigators attempted to do this indicate that changes in education and cardiovascular risk account for only a modest proportion of observed reduction in prevalence or incidence $[21,37,38]$. The interesting implication would be that other unanticipated, unmeasured and uncontrolled secular changes in population characteristics may have had an important impact. Similar studies should be carried out in the future to monitor the impact of prevention programs on the future scale of the dementia epidemic.

\section{Conclusions}

The best available evidence suggests that the age-specific prevalence of dementia is unlikely to change significantly in coming years, even if the incidence of dementia falls in response to secular improvements in public health in highincome countries. This conclusion remains provisional, given the limited data available on secular trends and the heterogeneity in study findings. Prudent policymakers should exercise due caution, being swayed neither by individual studies nor by Pollyannaish statements, such as expressed in a recent Lancet editorial [63]:

The projections of the ADI report for 2050 are alarming, but it is important to bear in mind that they are just that - projections.... The opportunity is here to ensure that the grim outlook for dementia in 2050, especially in low-income and middle-income countries, becomes nothing more than a work of fiction.

Future projections [3] may actually turn out to be conservative, particularly for low- and middle-income countries, should effective public health action not be taken. Under currently foreseeable scenarios, they should be considered as constituting the mid range of expectations. More research into national and regional trends in disease frequency, linked to changes in exposure levels to known risk factors, is urgently required.

\footnotetext{
Abbreviations

AD: Alzheimer's disease; ADI: Alzheimer's Disease International;

AGECAT: Automated Geriatric Examination for Computer Assisted Taxonomy; AHR: adjusted hazard ratio; AOR: adjusted odds ratio; BMI: body mass index; DSM: Diagnostic and Statistical Manual of Mental Disorders; GMS: Geriatric Mental State Examination; HDL: high-density lipoprotein; HRS: Health and Retirement Study; IADL: instrumental activities of daily living; ICD: International Classification of Diseases; MMSE: Mini Mental State Examination; MRC CFAS: Medical Research Council Cognitive function and Ageing Study; NINCDS-ADRDA: National Institute of Neurological and Communicative Disorders and Stroke and the Alzheimer's Disease and Related Disorders Association; NINDS/AIREN: National Institute of
} 
Neurological Disorders and Stroke and Association Internationale pour la Recherche et l'Enseignement en Neurosciences; RR: relative risk; VaD: vascular dementia.

\section{Acknowledgments}

AMP was supported by Medical Research Council grant MR/K021907/1. MP receives salary support from the National Institute for Health Research Mental Health Biomedical Research Centre at South London and Maudsley NHS Foundation Trust and King's College London. An earlier version of this work was published as Chapter 4 in the Alzheimer's Disease International World Alzheimer Report 2015: The Global Impact of Dementia: An Analysis of Prevalence, Incidence, Cost and Trends [3].

\section{Funding}

The Global Observatory for Ageing and Dementia Care is supported by a block grant from Alzheimer's Disease International to King's College London for their work on the World Alzheimer Reports and related activities. The 2015 World Alzheimer Report was supported by a grant from Bupa to Alzheimer's Disease International. The sponsors of the study had no role in study design, data collection, data analysis, data interpretation or writing of the manuscript.

\section{Availability of supporting data}

All data used and summarised for this review are available in the referenced published original papers.

\section{Authors' contributions}

All of the authors worked collectively to develop the protocols and methods described in this paper. GCA, MG, YTW and AMP carried out the initial systematic reviews, supplemented by MP. MP conducted the analyses and drafted the manuscript. All authors reviewed the manuscript and provided further contributions and suggestions. All authors had full access to all of the data in the study, and all authors read and approved the final manuscript. All authors and the corresponding author had final responsibility for the decision to submit the manuscript for publication.

\section{Competing interests}

The authors declare that they have no competing interests.

\section{Consent for publication}

Not applicable.

\section{Ethical approval and consent to participate}

Not applicable. In this review, we relied upon aggregated previously published data only.

\section{Author details}

${ }^{1}$ The Global Observatory for Ageing and Dementia Care, Health Service \& Population Research Department, Institute of Psychiatry, Psychology and Neuroscience, King's College London, PO 36, David Goldberg Centre, De Crespigny Park, London SE5 8AF, UK. ²Department of Public Health and Primary Care, School of Clinical Medicine, University of Cambridge, Cambridge, UK. ${ }^{3}$ Department of Psychiatry, University of Geneva, Geneva, Switzerland. ${ }^{4}$ Cambridge Institute of Public Health, University of Cambridge, Cambridge, UK.

\section{Received: 24 March 2016 Accepted: 20 April 2016}

\section{Published online: 30 July 2016}

\section{References}

1. Prince MJ, Jackson J, editors. World Alzheimer Report 2009. London: Alzheimer's Disease International; 2009.

2. Alzheimer's Disease International. Policy brief for G8 heads of government: the global impact of dementia 2013-2050. London: Alzheimer's Disease International; 2013

3. Prince M, Wimo AGM, Ali GC, Wu YT, Prina M. World Alzheimer Report 2015: the global impact of dementia: an analysis of prevalence, incidence, cost and trends. London: Alzheimer's Disease International; 2015.

4. Prince M, Bryce R, Albanese E, Wimo A, Ribeiro W, Ferri CP. The global prevalence of dementia: a systematic review and metaanalysis. Alzheimers Dement. 2013;9:63-75.
5. Ferri CP, Prince M, Brayne C, Brodaty H, Fratiglioni L, Ganguli M, et al. Global prevalence of dementia: a Delphi consensus study. Lancet. 2005;366:2112-7.

6. Langa KM. Is the risk of Alzheimer's disease and dementia declining? Alzheimers Res Ther. 2015;7:34

7. Prince M, Albanese E, Guerchet M, Prina M. World Alzheimer Report 2014: dementia and risk reduction. an analysis of protective and modifiable risk factors. London: Alzheimer Disease International; 2014.

8. Norton S, Matthews FE, Barnes DE, Yaffe K, Brayne C. Potential for primary prevention of Alzheimer's disease: an analysis of population-based data. Lancet Neurol. 2014;13:788-94.

9. Prince MJ, Wu F, Guo Y, Gutierrez Robledo LM, O'Donnell M, Sullivan R, et al. The burden of disease in older people and implications for health policy and practice. Lancet. 2015;385:549-62.

10. Feigin VL, Lawes CM, Bennett DA, Barker-Collo SL, Parag V. Worldwide stroke incidence and early case fatality reported in 56 population-based studies: a systematic review. Lancet Neurol. 2009;8:355-69.

11. Critchley J, Liu J, Zhao D, Wei W, Capewell S. Explaining the increase in coronary heart disease mortality in Beijing between 1984 and 1999. Circulation. 2004;110:1236-44.

12. Gupta R, Joshi P, Mohan V, Reddy KS, Yusuf S. Epidemiology and causation of coronary heart disease and stroke in India. Heart. 2008;94:16-26.

13. Gaziano TA, Bitton A, Anand S, Brahams-Gessel S, Murphy A. Growing epidemic of coronary heart disease in low- and middle-income countries. Curr Probl Cardiol. 2010;35:72-115.

14. Anand SS, Yusuf S. Stemming the global tsunami of cardiovascular disease. Lancet. 2011;377:529-32.

15. Mackenbach JP, Karanikolos M, Looman CW. The rise of mortality from mental and neurological diseases in Europe, 1979-2009: observational study. BMC Public Health. 2014;14:840. doi:10.1186/1471-2458-14-840.

16. Howse K, Harper S. Review of longevity trends in the United Kingdom to 2025 and beyond. J Popul Ageing. 2008;1:225-40.

17. Prince M, Acosta D, Ferri CP, Guerra M, Huang Y, Rodriguez JJ, et al. Dementia incidence and mortality in middle-income countries, and associations with indicators of cognitive reserve: a 10/66 Dementia Research Group population-based cohort study. Lancet. 2012;380:50-8.

18. Perkins AJ, Hui SL, Ogunniyi A, Gureje O, Baiyewu O, Unverzagt FW, et al. Risk of mortality for dementia in a developing country: the Yoruba in Nigeria. Int J Geriatr Psychiatry. 2002;17:566-73.

19. Nitrini R, Caramelli P, Herrera Jr E, de Castro I, Bahia VS, Anghinah R, et al. Mortality from dementia in a community-dwelling Brazilian population. Int J Geriatr Psychiatry. 2005;20:247-53.

20. Dewey ME, Saz P. Dementia, cognitive impairment and mortality in persons aged 65 and over living in the community: a systematic review of the literature. Int J Geriatr Psychiatry. 2001;16:751-61.

21. Langa KM, Larson EB, Karlawish JH, Cutler DM, Kabeto MU, Kim SY, et al. Trends in the prevalence and mortality of cognitive impairment in the United States: is there evidence of a compression of cognitive morbidity? Alzheimers Dement. 2008;4:134-44.

22. Kokmen E, Chandra V, Schoenberg BS. Trends in incidence of dementing illness in Rochester, Minnesota, in three quinquennial periods, 1960-1974. Neurology. 1988;38:975-80.

23. Rorsman B, Hagnell O, Lanke J. Prevalence and incidence of senile and multiinfarct dementia in the Lundby Study: a comparison between the time periods 1947-1957 and 1957-1972. Neuropsychobiology. 1986;15:122-9.

24. Barnes DE, Yaffe $K$. The projected effect of risk factor reduction on Alzheimer's disease prevalence. Lancet Neurol. 2011;10:819-28.

25. Lincoln P, Fenton K, Alessi C, Prince M, Brayne C, Wortmann M, et al. The Blackfriars Consensus on brain health and dementia. Lancet. 2014;383:1805-6.

26. World Health Organization. Dementia: a public health priority. Geneva: World Health Organization; 2012.

27. Matthews FE, Arthur A, Barnes LE, Bond J, Jagger C, Robinson L, et al. A two-decade comparison of prevalence of dementia in individuals aged 65 years and older from three geographical areas of England: results of the Cognitive Function and Ageing Study I and II. Lancet. 2013;382:1405-12.

28. Lobo A, Saz P, Marcos G, Dia JL, De-la-Camara C, Ventura T, et al. Prevalence of dementia in a southern European population in two different time periods: the ZARADEMP Project. Acta Psychiatr Scand. 2007;116:299-307

29. Qiu C, von Strauss E, Backman L, Winblad B, Fratiglioni L. Twenty-year changes in dementia occurrence suggest decreasing incidence in central Stockholm, Sweden. Neurology. 2013;80:1888-94. 
30. Wiberg P, Waern M, Billstedt E, Ostling S, Skoog I. Secular trends in the prevalence of dementia and depression in Swedish septuagenarians 1976-2006. Psychol Med. 2013;43:2627-34.

31. Rocca WA, Petersen RC, Knopman DS, Hebert LE, Evans DA, Hall KS, et al. Trends in the incidence and prevalence of Alzheimer's disease, dementia, and cognitive impairment in the United States. Alzheimers Dement. 2011;7:80-93.

32. Doblhammer G, Fink A, Fritze T. Short-term trends in dementia prevalence in Germany between the years 2007 and 2009. Alzheimers Dement. 2015;11:291-9.

33. Mathillas J, Lovheim H, Gustafson Y. Increasing prevalence of dementia among very old people. Age Ageing. 2011;40:243-9.

34. Sekita A, Ninomiya T, Tanizaki Y, Doi Y, Hata J, Yonemoto K, et al. Trends in prevalence of Alzheimer's disease and vascular dementia in a Japanese community: the Hisayama Study. Acta Psychiatr Scand. 2010;122:319-25.

35. Wakutani Y, Kusumi M, Wada K, Kawashima M, Ishizaki K, Mori M, et al. Longitudinal changes in the prevalence of dementia in a Japanese rural area. Psychogeriatrics. 2007;7:150-4

36. Gao S, Ogunniyi A, Hall KS, Baiyewu O, Unverzagt FW, Lane KA, et al. Dementia incidence declined in African-Americans but not in Yoruba. Alzheimers Dement. 2016:12:244-51.

37. Satizabal CL, Beiser AS, Chouraki V, Chêne G, Dufouil C, Seshadri S. Incidence of dementia over three decades in the Framingham Heart Study. N Engl J Med. 2016;374:523-32

38. Grasset L, Brayne C, Joly P, Jacamin-Gadda H, Peres K, Foubert-Samier A, et al. Trends in dementia incidence: evolution over a 10-year period in France. Alzheimers Dement. 2016;12:272-80.

39. Schrijvers EM, Verhaaren BF, Koudstaal PJ, Hofman A, Ikram MA, Breteler MM. Is dementia incidence declining? Trends in dementia incidence since 1990 in the Rotterdam Study. Neurology. 2012;78:1456-63.

40. Doblhammer G, Fink A, Zylla S, Willekens F. Compression or expansion of dementia in Germany? An observational study of short-term trends in incidence and death rates of dementia between 2006/07 and 2009/10 based on German health insurance data. Alzheimers Res Ther. 2015;7:66

41. Sposato LA, Kapral MK, Fang J, Gill SS, Hackam DG, Cipriano LE, et al. Declining incidence of stroke and dementia: coincidence or prevention opportunity? JAMA Neurol. 2015;72:1529-31.

42. Li S, Yan F, Li G, Chen C, Zhang W, Liu J, et al. Is the dementia rate increasing in Beijing? Prevalence and incidence of dementia 10 years later in an urban elderly population. Acta Psychiatr Scand. 2007;115:73-9.

43. Dodge HH, Buracchio TJ, Fisher GG, Kiyohara Y, Meguro K, Tanizaki Y, et al. Trends in the prevalence of dementia in Japan. Int J Alzheimers Dis. 2012;2012:956354. doi:10.1155/2012/956354.

44. Kim YJ, Han JW, So YS, Seo JY, Kim KY, Kim KW. Prevalence and trends of dementia in Korea: a systematic review and meta-analysis. J Korean Med Sci. 2014;29:903-12.

45. Chan KY, Wang W, Wu JJ, Liu L, Theodoratou E, Car J, et al. Epidemiology of Alzheimer's disease and other forms of dementia in China, 1990-2010: a systematic review and analysis. Lancet. 2013;381:2016-23.

46. Wu YT, Lee HY, Norton S, Prina AM, Fleming J, Matthews FE, et al. Period, birth cohort and prevalence of dementia in mainland China, Hong Kong and Taiwan: a meta-analysis. Int J Geriatr Psychiatry. 2014;29:1212-20.

47. Wu YT, Brayne C, Matthews FE. Prevalence of dementia in East Asia: a synthetic review of time trends. Int J Geriatr Psychiatry. 2015;30:793-801.

48. Yang $G$, Wang $Y$, Wu $Y$, Yang J, Wan $X$. The road to effective tobacco control in China. Lancet. 2015;385:1019-28.

49. Adair LS, Gordon-Larsen P, Du SF, Zhang B, Popkin BM. The emergence of cardiometabolic disease risk in Chinese children and adults: consequences of changes in diet, physical activity and obesity. Obes Rev. 2014;15 Suppl 1:49-59. doi:10.1111/obr.12123.

50. Loef M, Walach H. Midlife obesity and dementia: meta-analysis and adjusted forecast of dementia prevalence in the United States and China. Obesity (Silver Spring). 2013;21:E51-5.

51. Satizabal CL, Beiser A, Chêne G, Chouraki VA, Himali JJ, Preis SR, et al. Temporal trends in dementia incidence in the Framingham Study [abstract O5-03-05]. Alzheimers Dement. 2014;10(4 Suppl):296.

52. Gao S, Ogunniyi A, Hall KS, Baiyewu O, Unverzagt F, Lane KA, et al. Alzheimer's disease incidence declined in African Americans, but not in Yoruba [abstract 05-03-06]. Alzheimers Dement. 2014;10(4 Suppl):296-7.
53. Joly P, Touraine C, Georget A, Dartigues JF, Commenges D, Jacqmin-Gadda H. Prevalence projections of chronic diseases and impact of public health intervention. Biometrics. 2013;69:109-17.

54. Jacamin-Gadda H, Alperovitch A, Montlahuc C, Commenges D, Leffondre K, Dufouil $C$, et al. 20-Year prevalence projections for dementia and impact of preventive policy about risk factors. Eur J Epidemiol. 2013;28:493-502.

55. Prince M, Prina M, Guerchet M. World Alzheimer Report 2013: journey of caring: an analysis of long-term care for dementia. London: Alzheimer's Disease International; 2013.

56. Albanese E, Liu Z, Acosta D, Guerra M, Huang Y, Jacob K, et al. Equity in the delivery of community healthcare to older people: findings from 10/66 Dementia Research Group cross-sectional surveys in Latin America, China, India and Nigeria. BMC Health Serv Res. 2011;11:153.

57. Dewey ME, Copeland JRM. Computerized psychiatric diagnosis in the elderly: AGECAT. J Microcomp Appl. 1986;9:135-40.

58. Prince $M$, Acosta D, Chiu H, Scazufca M, Varghese M. Dementia diagnosis in developing countries: a cross-cultural validation study. Lancet. 2003;361:909-17.

59. Prince MJ, de Rodriguez $J$, Noriega L, Lopez A, Acosta D, Albanese E, et al. The 10/66 Dementia Research Group's fully operationalised DSM-IV dementia computerized diagnostic algorithm, compared with the 10/66 dementia algorithm and a clinician diagnosis: a population validation study. BMC Public Health. 2008:8:219.

60. Ford ES, Ajani UA, Croft JB, Critchley JA, Labarthe DR, Kottke TE, et al. Explaining the decrease in U.S. deaths from coronary disease, 1980-2000. N Engl J Med. 2007:356:2388-98.

61. Vartiainen E, Laatikainen T, Peltonen M, Juolevi A, Männistö S, Sundvall J, et al. Thirty-five-year trends in cardiovascular risk factors in Finland. Int J Epidemiol. 2010;39:504-18.

62. Laatikainen T, Critchley J, Vartiainen E, Salomaa V, Ketonen M, Capewell S. Explaining the decline in coronary heart disease mortality in Finland between 1982 and 1997. Am J Epidemiol. 2005;162:764-73.

63. A global assessment of dementia, now and in the future [editorial]. Lancet. 2015;386:931.

\section{Submit your next manuscript to BioMed Central and we will help you at every step:}

- We accept pre-submission inquiries

- Our selector tool helps you to find the most relevant journal

- We provide round the clock customer support

- Convenient online submission

- Thorough peer review

- Inclusion in PubMed and all major indexing services

- Maximum visibility for your research

Submit your manuscript at www.biomedcentral.com/submit 